\title{
Effect of Different Nitrogen Fertilizer Types and Application Measures on Temporal and Spatial Variation of Soil Nitrate-Nitrogen at Cucumber Field
}

\author{
Zhaopeng Ou Yang ${ }^{1}$, Xurong $\mathrm{Mei}^{2}$, Fan $\mathrm{Gao}^{1}$, Yuzhong $\mathrm{Li}^{2}$, Jiaxuan Guo ${ }^{1}$ \\ ${ }^{1}$ Beijing Key Laboratory of New Technology in Agricultural Application, College of Plant and Technology, Beijing University of \\ Agriculture, Beijing, China; ${ }^{2}$ Water Resources and Dryland Farming Laboratory, Institute of Agricultural Environment and Sustain- \\ able Development, Chinese Academy of Agricultural Sciences, Beijing, China. \\ Email: guojx_hh@163.com
}

Received November $12^{\text {th }}, 2012$; revised December $13^{\text {th }}, 2012$; accepted January $7^{\text {th }}, 2013$

\begin{abstract}
Nitrate-nitrogen content of groundwater are ever-increasing in underneath vegetable growing areas, in this paper, based on field test of cucumber cultivated in Solar Greenhouse in North China, we study the effects of different nitrogen fertilizer application levels (250,300, $350 \mathrm{~kg} / \mathrm{hm}^{2}$ ) and different nitrogen fertilizer types (urea, urea + nitrification inhibitor, slow-release fertilizer) on temporal and spatial variation of soil nitrate-nitrogen content in different soil depth, soil nitrogen fertilizer retention and nitrogen use efficiency during cucumber growth period. The results show that, in the cases of nitrogen fertilizer types (urea and urea + nitrification inhibitor), for surface soil ( 0 - $40 \mathrm{~cm}$ soil depth), the temporal trend of soil nitrate-nitrogen content variation is similar: during the early stage of cucumber growth, soil nitrate-nitrogen content is relatively high; during the middle stage of cucumber growth, as nitrogen is constantly being absorbed by the vegetable, soil nitrate-nitrogen content decrease; during the late stage of cucumber growth, soil nitrate-nitrogen content increase, and increase more significantly when nitrification inhibitor is added in the fertilizer. For deep soil layer (40 - $100 \mathrm{~cm}$ depth), when only using urea, the temporal trend of soil nitrate-nitrogen content variation is that of continuous increase, when adding nitrification inhibitor, the temporal trend of soil nitrate-nitrogen content variation is that of insignificant increase. In the case of slow-release fertilizer, for both surface soil and deep soil layer, the temporal trend of soil nitrate-nitrogen content variation is that of continuous decrease. For all three types of nitrogen fertilizer, as fertilization level increase, soil nitrate-nitrogen content in various soil layers increase with it. In the case of fertilization at $300 \mathrm{~kg} / \mathrm{hm}^{2}$ and $350 \mathrm{~kg} / \mathrm{hm}^{2}$, adding nitrification inhibitor can increase soil retention of nitrogen fertilizer. This study suggests that adding nitrification inhibitors can increase soil retention of nitrogen fertilizer, decrease nitrate-nitrogen leaching downward, thereby reducing the pollution to groundwater.
\end{abstract}

Keywords: Solar Greenhouse; Cucumber; Nitrate-Nitrogen; Nitrogen Retention

\section{Introduction}

In China, facility vegetable cultivation is developing rapidly, up to the year of 2010, the total area of facility vegetable cultivation in China is 4.667 million $\mathrm{hm}^{2}$, amounting to $80 \%$ of facility horticulture in the world. In China's current facility vegetable production, fertilizers (especially nitrogen fertilizer) application is too much, significantly exceeding what the crops need, excessive fertilizer application not only waste resources and decrease efficiency of fertilizer usage, but also pollute groundwater, that is, as excessive nitrogen fertilizer infiltrate downward with irrigation, the content of nitrate-nitrogen in groundwater exceed the safety standard, thereby pose a threat to the safety of people's drinking water. The inter- national community is increasingly concerned with the problem of nitrate pollution in groundwater [1-3]. Groundwater pollution by soil nitrate-nitrogen is getting worse, the content of nitrate-nitrogen in groundwater is constantly rising with the amount of nitrogen fertilizer application [4,5]; Alberts and Spomer [6] showed that in the case of excessive fertilization, more than $85 \%$ of soil nitrate-nitrogen is lost through soil leaching and runoff with irrigation; nitrate content in Beijing area's groundwater continues to rise, the rate of increase is $1.25 \mathrm{mg} / \mathrm{L}$ per year, the area of pollution is already exceeding 3000 $\mathrm{hm}^{2}$ [7]; Liu Hongbin [8] monitored shallow groundwater samples from 43 protected vegetable fields throughout Beijing, the average nitrate-nitrogen content is 72.4 $\mathrm{mg} / \mathrm{L}$, all of the samples have nitrate-nitrogen content 
exceeding international safety standards for drinking water. In this paper, based on field study of cucumber cultivated in solar Greenhouse, we study the effects of different nitrogen fertilizer application levels and different nitrogen fertilizer types on temporal and spatial variation of soil nitrate-nitrogen content, yield, and nitrogen use efficiency during cucumber growth period. Our purpose is to provide reasonable suggestions for cucumber production, aiming to reduce nitrate leaching during vegetable production, so as to reduce groundwater pollution.

\section{Materials and Methods}

\subsection{Field Study Experimental Condition}

We conducted field test in the Solar Greenhouse of Science and Technology Park in Beijing Agriculture University. The field is located on the northern edge of the North China Plain $\left(116^{\circ} 18^{\prime} 12.5^{\prime \prime} \mathrm{E}, 40^{\circ} 05^{\prime} 28.1^{\prime \prime N}\right.$; an average elevation of $31.3 \mathrm{~m}$ ), belongs to the continental monsoon type with warm and semi-humid climate, the average annual precipitation is $616 \mathrm{~mm}$, resources of sunlight and heat are rich, average annual temperature is $11.9^{\circ} \mathrm{C}$, annual daytime sunshine hours are $2714 \mathrm{~h}$, annual frost-free days are $200-203 \mathrm{~d}$. Soil texture of the field is that of aquic soil, consists soil organic matter $17.55 \mathrm{~g} / \mathrm{kg}$, total nitrogen $1.08 \mathrm{~g} / \mathrm{kg}$, alkali-hydrolyzable nitrogen $100.18 \mathrm{mg} / \mathrm{kg}$, available phosphorus $27.33 \mathrm{mg} / \mathrm{kg}$, available potassium $150.88 \mathrm{mg} / \mathrm{kg}$.

\subsection{Research Materials and Experimental Design}

Field test was conducted during the whole growth period of Cucumber in solar greenhouse from March to June in 2011. Cucumber varieties Han Yan No. 2 is our research material, seedlings were transplanted in March 8, 2011, and harvested in June 20th, 2011. The field is divided into plots, each plot is the size of $1.5 \mathrm{~m} \times 5.6 \mathrm{~m}$, two rows of cucumbers are planted in each plot, row spacing is $60 \mathrm{~cm}$, and individual strain spacing is $40 \mathrm{~cm}$. We designed four different levels of nitrogen fertilization, which respectively is, CK (blank control, no fertilizer); $\mathrm{N} 1$ (pure nitrogen $250 \mathrm{~kg} / \mathrm{hm}^{2}$ ); N2 (pure nitrogen 300 $\mathrm{kg} / \mathrm{hm}^{2}$ ); N3 (pure nitrogen $350 \mathrm{~kg} / \mathrm{hm}^{2}$ ). Among which, $150 \mathrm{~kg} / \mathrm{hm}^{2}$ is used as base fertilizer, the remaining amount is used as topdressing during cucumber growth period; three different types of nitrogen fertilizer are used at each application amount, the three types respectively is, T1 (urea), T2 (urea + nitrification inhibitor, at ratio of 5:1), T3 (slow-release fertilizer). Except the plot of blank control, each experimental plot is given the same amount of organic fertilizer as well as phosphate fertilizer and potash fertilizer, wherein all the organic fertilizer and phosphate fertilizer are used as base fertilizer, whereas $60 \%$ potash fertilizer is used as base fertilizer, the remaining $40 \%$ as topdressing used together with nitrogen fertileizer. Detailed fertilization designs are shown in Table 1.

\subsection{Sample Collection and Determination}

Cucumber yield is determined by real time sample picking during cucumber growth period; staring from seedling transplantation, undisturbed soil samples (in the depth range of $0-100 \mathrm{~cm}$ ) at $20 \mathrm{~cm}$ layer intervals are taken with soil drill every ten days; in each experimental plot, both prior to seedling transplantation and after harvesting, soil samples (in the depth range of $0-200 \mathrm{~cm}$ ) are taken at three ground points selected according to trigonometry method. Soil nitrate-nitrogen and ammonium-nitrogen content is determined by automatic intermittent analyzer (SMARTCHEM140 from French AMS Group); after harvesting, from each experimental plot, randomly take three plant samples, separate the root, stem and leaves, using the drying method to determine plant water content, using $\mathrm{H}_{2} \mathrm{SO}_{4}-\mathrm{H}_{2} \mathrm{O}_{2}$ boiling method $[9,10]$ to determine plant total nitrogen content through SMARTCHEM140 automatic intermittent analyzer; cucumber fruit total nitrogen content is determined using samples picked at different stages of cucumber growth.

\subsection{Calculation Method}

$$
\mathrm{R}=(\mathrm{A}-\mathrm{B}) / \mathrm{C} \times 100 \quad[11]
$$

Wherein, R represents Soil nitrogen fertilizer retention rate; A represents the cumulative amount of inorganic nitrogen (the total content of nitrate-nitrogen and ammonium-nitrogen) within soil depth of 0 to $200 \mathrm{~cm}$ at each

Table 1. Fertilization trial design.

\begin{tabular}{ccccc}
\hline Fertilizer types fertilization methods & Organic fertilizer $\left(\mathrm{kg} / \mathrm{hm}^{2}\right)$ & $\mathrm{N}\left(\mathrm{kg} / \mathrm{hm}^{2}\right)$ & $\mathrm{P}_{2} \mathrm{O}_{5}\left(\mathrm{~kg} / \mathrm{hm}^{2}\right)$ & $\mathrm{K} \mathrm{K}_{2} \mathrm{O}\left(\mathrm{kg} / \mathrm{hm}^{2}\right)$ \\
\hline Base fertilizer & 7500 & 150 & 250 & 150 \\
& & 100 & 0 & 100 \\
Top dressing & 0 & 150 & 200 & \\
\hline
\end{tabular}


plot that receive different level of fertilization; B represents the cumulative amount of inorganic nitrogen within soil depth of 0 to $200 \mathrm{~cm}$ at the blank control plot that receive no fertilization; $C$ represents the total amount of nitrogen fertilizer used in each experiment plot.

$$
\mathrm{R}=(\mathrm{H}-\mathrm{Ho}) / \mathrm{F} \times 100 \text { [12] }
$$

$\mathrm{R}$ represents Nitrogen fertilizer Use Efficiency; H represents cucumber nitrogen absorption in crops receiving fertilization; Ho represents cucumber nitrogen absorption in crops receiving no fertilization; F represents the total amount of nitrogen fertilizer used in the plot.

\section{Results and Analysis}

\subsection{Effect of Different Treatments on Cucumber Yield}

As shown from Figure 1, compared with blank control plot, all fertilized plots have higher cucumber yield, the difference in crop yield is significant, fertilization can increase crop yield by $32.27 \%-94.24 \% ; 300 \mathrm{~kg} / \mathrm{hm}^{2}$ (N2) urea fertilization achieve the highest yield (87228.97 $\mathrm{kg} / \mathrm{hm}^{2}$ ), $350 \mathrm{~kg} / \mathrm{hm}^{2}$ (N3) slow-release fertilizer fertilization achieve the lowest yield $\left(59397.11 \mathrm{~kg} / \mathrm{hm}^{2}\right)$. When the amount of nitrogen fertilizer application is at the level of $250 \mathrm{~kg} / \mathrm{hm}^{2}$ (N1) or $350 \mathrm{~kg} / \mathrm{hm}^{2}$ (N3), there is no significant difference in crop yield among different types of nitrogen fertilizer; When the amount of nitrogen fertilizer application is at the level of $300 \mathrm{~kg} / \mathrm{hm}^{2}$ (N2), there is significant difference $(p<0.05)$ in crop yield among different types of nitrogen fertilizer. When the type of nitrogen fertilizer is urea + nitrification inhibitor (T2) or slow-release fertilizer (T3), there is no significant difference in crop yield among different application of nitrogen fertilizer; When the type of nitrogen fertilizer is urea (T1), crop yield at the level of $300 \mathrm{~kg} / \mathrm{hm}^{2}$ (N2) is significantly higher than that at the other two nitrogen levels.

\subsection{Effect of Different Treatments on Temporal and Spatial Variation of Soil Nitrate-Nitrogen Content during Cucumber Growth Period}

Fertilizer nitrate-nitrogen is readily available for direct use by vegetable roots, because nitrate-nitrogen has low affinity to soil colloid, it can easily leaching downward $[13,14]$. As shown from Figure 2, in the case of blank control plot (CK), during the early stage of cucumber growth, nitrate-nitrogen content in surface soil is significantly higher than that in soil layers deeper than $40 \mathrm{~cm}$, then afterwards irrigation increase nitrate-nitrogen content in the deep soil layer, during later stages of cucumber growth, as more nitrate-nitrogen is consumed by the crop and with multiple irrigation, nitrate-nitrogen content is relatively low both in surface soil and in soil layers deeper than $40 \mathrm{~cm}$. In the case of urea (T1) and urea + nitrification inhibitor (T2) application plots, due to prior application of base fertilizer, during the early stage of cucumber growth, nitrate-nitrogen content in surface soil (0 - $40 \mathrm{~cm}$ depth) achieves higher accumulation; during middle stage of cucumber growth, as more nitrate-nitrogen is consumed by the crop, surface soil nitrate-nitrogen content decrease; during late stage, surface soil nitratenitrogen content accumulate again, furthermore, under the same amount of nitrogen fertilizer application, surface soil nitrate-nitrogen content accumulate higher in the case of urea + nitrification inhibitor (T2) than in the case of urea (T1); the trend of nitrate-nitrogen variation in soil layers deeper than $40 \mathrm{~cm}$ is different, in the case of urea (T1), due to multiple irrigation during cucumber growth period, nitrate nitrogen obviously leaching downward, nitrate-nitrogen content increased signifycantly in soil layer of the $80-100 \mathrm{~cm}$ depth, whereas in

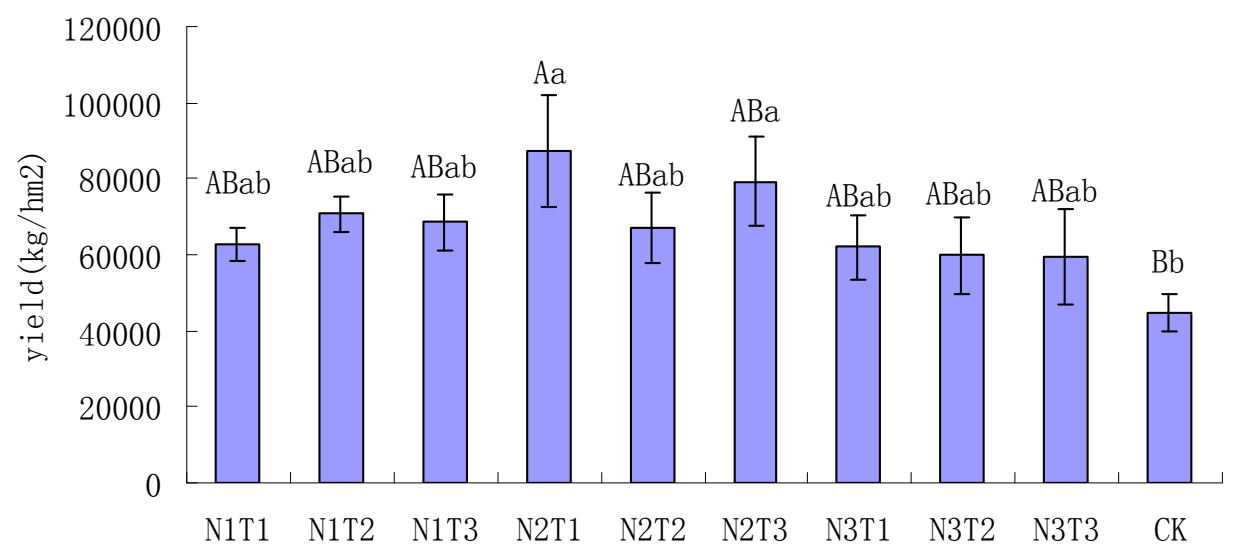

Note: Upper and lower case letters indicated significance of $p<0.01$ and $p<0.05$ by Duncan's significant test

Figure 1. Effect of different nitrogen levels and nitrogen fertilizer types on the yield of cucumber. 
the case of adding nitrification inhibitor (T2), the leaching phenomenon is not obvious, during cucumber growth period, nitrate-nitrogen content in soil layer deeper than $80 \mathrm{~cm}$ did not increase significantly. In the case of slowrelease fertilizer (T3), during cucumber growth period, nitrate-nitrogen content in the soil layer $(0-60 \mathrm{~cm})$ increase during the early stage of cucumber growth, then decrease afterwards with multiple irrigation and as more nitrate-nitrogen is consumed by the crop. Of all three types of fertilizer, as the amount of nitrogen fertilizer application increase, nitrate-nitrogen content in soil layer of similar depth also showed an increasing trend.

As shown from Table 2, of the last samples taken on June 20, 2011, in terms of relative $\mathrm{NO}_{3}-\mathrm{N}$ accumulation, that is, cumulative nitrate-nitrogen content in surface soil $(0-40 \mathrm{~cm})$ relative to that in entire soil $(0-100 \mathrm{~cm})$, cumulative nitrate-nitrogen content in entire soil (0 - 100 $\mathrm{cm}$ ) is regarded as $100 \%$, relative $\mathrm{NO}_{3}-\mathrm{N}$ accumulation is cumulative nitrate-nitrogen content in surface soil (0 - 40 $\mathrm{cm})$ divided by that in entire soil $(0-100 \mathrm{~cm})$. The results show that, when the amount of nitrogen fertilizer application is at the level of $300 \mathrm{~kg} / \mathrm{hm}^{2}(\mathrm{~N} 2)$, in the case of urea + nitrification inhibitor (T2), relative $\mathrm{NO}_{3}-\mathrm{N}$ accumulation is $68.6 \%$, which is the highest among all results. At each level of nitrogen fertilizer application, it is always in the case of urea + nitrification inhibitor (T2), when relative $\mathrm{NO}_{3}-\mathrm{N}$ accumulation is the highest in the group, which suggest that adding nitrification inhibitor can reduce nitrogen leaching downward, thereby improve nitrate content in surface soil, so as to provide more nutrient for subsequent crop growth. In the case of urea (T1) and urea + nitrification inhibitor (T2), as the level of nitrogen fertilizer increase, relative $\mathrm{NO}_{3}-\mathrm{N}$ accumulation also increases; in the case of slow-release fertilizer (T3), according to the level of nitrogen fertilizer, relative $\mathrm{NO}_{3}-\mathrm{N}$ accumulation from high to low is as such: N3 > $\mathrm{N} 1>\mathrm{N} 2$.

\subsection{Effect of Different Treatments on Soil Nitrogen Fertilizer Retention}

As shown from Table 3, as the level of nitrogen fertilizer increase, soil nitrogen retention increase accordingly; at the level of $350 \mathrm{~kg} / \mathrm{hm}^{2}$ (N3), soil nitrogen retention is $61.83 \%$, which is the highest among all results. In the case of urea + nitrification inhibitor (T2) and slow-release fertilizer (T3), as the level of nitrogen fertilizer increase, soil nitrogen retention also increase signifycantly; whereas in the case of urea (T1), at the level of $250 \mathrm{~kg} / \mathrm{hm}^{2}$ (N1), soil nitrogen retention is highest in the group. Soil nitrogen fertilizer retention of slow release fertilizer (T3) is significantly lower than that of the other two types of nitrogen fertilizer, which is due to the reason that slow release fertilizer (T3) is used entirely as base fertilizer, then after multiple irrigation throughout the growth period, significantly more nitrogen were leaching downward into the deeper soil, in the condition of this experiment, our result indicate that when $\mathrm{T} 3$ is used entirely as base fertilizer, more nitrogen fertilizer was leaching into deeper soil, causing greater harm to groundwater. In the case of $350 \mathrm{~kg} / \mathrm{hm}^{2}$ nitrogen level (N3), soil nitrogen fertilizer retention is higher in the presence of nitrification inhibitor (T2) than that of only using urea (T1), our result indicates that nitrification inhibitors can increase nitrogen retention rate, reduce leaching, thereby reducing pollution to groundwater.

\subsection{Effect of Different Treatments on Cucumber Nitrogen Fertilizer Use Efficiency}

As shown from Table 4, among different fertilization level, as the level of nitrogen fertilizer increase, cucumber nitrogen fertilizer use efficiency also increase, at the highest fertilization level $\left(350 \mathrm{~kg} / \mathrm{hm}^{2}\right)$, mean efficiency of three fertilizer types is $8.71 \%$, which is the highest among all fertilization levels. In the case of $350 \mathrm{~kg} / \mathrm{hm}^{2}$

Table 2. Relative $\mathrm{NO}_{3}-\mathrm{N}$ accumulation under different nitrogen levels and nitrogen fertilizer types.

\begin{tabular}{ccccccccccc}
\hline Treatments & N1T1 & N1T2 & N1T3 & N2T1 & N2T2 & N2T3 & N3T1 & N3T2 & N3T3 & CK \\
\hline Relative $\mathrm{NO}_{3}$-N accumulation & $50.0 \%$ & $51.3 \%$ & $45.1 \%$ & $50.6 \%$ & $53.5 \%$ & $39.3 \%$ & $59.9 \%$ & $68.6 \%$ & $52.0 \%$ & $38.6 \%$ \\
\hline
\end{tabular}

Table 3. Effect of different nitrogen levels and nitrogen fertilizer types on nitrogen retention of cucumber in solar greenhouse.

\begin{tabular}{|c|c|c|c|c|}
\hline Nitrogen types $\quad$ Nitrogen level & $250 \mathrm{~kg} / \mathrm{hm}^{2}$ & $300 \mathrm{~kg} / \mathrm{hm}^{2}$ & $350 \mathrm{~kg} / \mathrm{hm}^{2}$ & Mean \\
\hline Urea & $82.77 \%$ & $67.38 \%$ & $81.45 \%$ & $77.20 \%$ \\
\hline Urea + nitrification inhibitors & $48.56 \%$ & $66.05 \%$ & $88.70 \%$ & $67.77 \%$ \\
\hline Slow-release fertilizer & $5.41 \%$ & $13.30 \%$ & $15.35 \%$ & $11.35 \%$ \\
\hline Mean & $45.58 \%$ & $48.91 \%$ & $61.83 \%$ & \\
\hline
\end{tabular}


Table 4. Effect of different nitrogen levels and nitrogen fertilizer types on nitrogen use efficiency of cucumber in solar greenhouse.

\begin{tabular}{|c|c|c|c|c|}
\hline Fertilizer Types & $250 \mathrm{~kg} / \mathrm{hm}^{2}$ & $300 \mathrm{~kg} / \mathrm{hm}^{2}$ & $350 \mathrm{~kg} / \mathrm{hm}^{2}$ & Mean \\
\hline Urea & $4.58 \%$ & $9.18 \%$ & $7.76 \%$ & $7.17 \%$ \\
\hline Urea + nitrification inhibitor & $5.16 \%$ & $3.38 \%$ & $15.49 \%$ & $8.47 \%$ \\
\hline Slow-release fertilizer & $1.44 \%$ & $10.33 \%$ & $2.87 \%$ & $7.76 \%$ \\
\hline Mean & $3.73 \%$ & $7.63 \%$ & $8.71 \%$ & \\
\hline
\end{tabular}
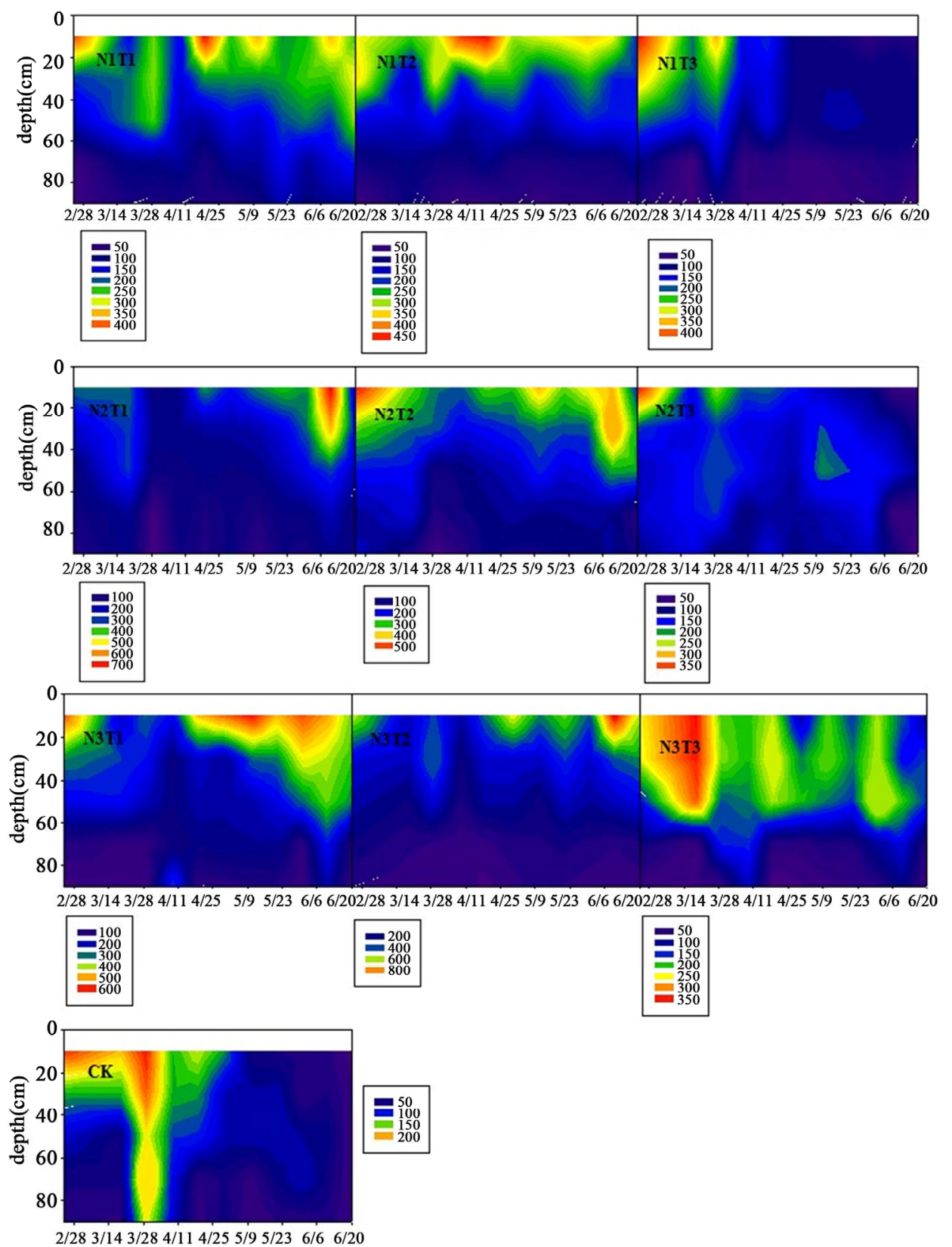

Figure 2. Effect of different nitrogen levels and nitrogen fertilizer types on temporal and spatial variation of soil nitrate of cucumber. 
nitrogen level (N3), of all fertilizer types, the highest efficiency $(15.49 \%)$ occurs with urea + nitrification inhibitor (T2), the lowest efficiency $(2.87 \%)$ occurs with slow release fertilizer (T3). In the case of $250 \mathrm{~kg} / \mathrm{hm}^{2}$ nitrogen level (N1), of all fertilizer types, the same trend of efficiency variation occurs as above. In the case of $300 \mathrm{~kg} / \mathrm{hm}^{2}$ nitrogen level (N2), of all fertilizer types, the contrary trend of efficiency variation occurs, the lowest efficiency (3.38\%) occurs with urea + nitrification inhibitor (T2), the highest efficiency (10.33\%) occurs with slow release fertilizer (T3).

In the case of urea (T1), the highest efficiency (9.18\%) occurs at $300 \mathrm{~kg} / \mathrm{hm}^{2}$ nitrogen level (N2), the lowest efficiency $(4.58 \%)$ occurs at $250 \mathrm{~kg} / \mathrm{hm}^{2}$ nitrogen level (N1). In the case of adding nitrification inhibitor (T2), the highest efficiency (15.49\%) occurs at $350 \mathrm{~kg} / \mathrm{hm}^{2}$ nitrogen (N3), the lowest efficiency (3.38\%) occurs at $300 \mathrm{~kg} / \mathrm{hm}^{2}$ nitrogen level (N2). In the case of slow-release fertilizer (T3), the highest efficiency (10.33\%) occurs at $300 \mathrm{~kg} / \mathrm{hm}^{2}$ (N2), which is also significantly higher than that of the other two nitrogen levels.

\section{Discussion}

Thoughtless application of excessive nitrogenous fertilizer not only can not improve crop yield [5,19], but instead can decline crop yield; excessive soil nitrate-nitrogen can not be effectively consumed by crops, instead vast amount of excess nitrogen is lost or runoff in a variety of ways $[15,20]$. Accumulation and variation of nitrate-nitrogen in soil layer of different depth is determined by a lot of influencing factors, such as soil texture, soil structure, soil residual nitrate-nitrogen content, nitrogen fertilization level and fertilization methods, rainfall and irrigation amount [16]. Yin Juan [17] showed that the larger the irrigation water quota, the more nitrogennitrate leaching downward with water into groundwater. Wei Yan [14] showed that drip irrigation and slowsipping irrigation are better than quick-flashing irrigation in reducing the amount of nitrate-nitrogen leaching downward, and can better hold nutrient distribution in surface soil for root growth; Liu Hongbin [18] showed in cabbage cultivated in the open field, as the amount of nitrogen fertilizer increase, soil nitrate-nitrogen content also increase linearly. Under our experimental condition, when the same type of nitrogen fertilizer is used, as the amount of nitrogen fertilizer increase, soil $\mathrm{NO}_{3}-\mathrm{N}$ content in various soil layers also increase. In the case of urea and urea + nitrification inhibitors, during the whole growth period of cucumber, the trend of nitrate-nitrogen content variation in surface soil layer $(0-40 \mathrm{~cm})$ is that of decreasing in the early period and increasing in the later period; when only urea is used, the trend of nitrate-nitrogen content variation in deep soil layer (40 $100 \mathrm{~cm}$ ) is that of continuous increase, when urea + nitri- fication inhibitor is used, nitrate-nitrogen content in deep soil layer did not significantly increase during the whole period of cucumber growth. In the case of slow-release fertilizer, during the whole growth period of cucumber, in both surface and deep soil layers, the trend of soil $\mathrm{NO}_{3}-\mathrm{N}$ content variation is that of continuous decrease. Whatever amount of nitrogen fertilizer is used, it is always in the case of adding nitrification inhibitor (T2) that relative $\mathrm{NO}_{3}-\mathrm{N}$ accumulation (cumulative nitrate-nitrogen content in surface soil relative to that in full soil depth) is the highest, the result suggests that adding nitrification inhibitor can reduce nitrate-nitrogen leaching downward, thereby reducing pollution to groundwater. As the amount of nitrogen fertilizer increase, soil nitrogen retention also increase, soil nitrogen fertilizer retention of slow release fertilizer (T3) is significantly lower than that of the other two types of nitrogen fertilizer, which suggests that this fertilization method (T3) is unsuitable in crop production.

\section{Conclusion}

In the case of urea and urea + nitrification inhibitor, during cucumber growth period, the temporal trend of nitrate-nitrogen content variation in surface soil $(0-40 \mathrm{~cm})$ is that of increasing in the early period, decreasing in the middle period as more nitrate-nitrogen are continuously absorbed by flourishing cucumber, and increasing again in the late period; when adding nitrification inhibitors, the temporal trend of nitrate-nitrogen content variation in middle soil layer $(40-60 \mathrm{~cm})$ is that of moderate increase, the temporal trend of nitrate-nitrogen content variation in deep soil layer $(60-100 \mathrm{~cm})$ is that of insignificant increase; when only using urea, the temporal trend of ni trate-nitrogen content variation in deep soil layer (40 $100 \mathrm{~cm}$ ) is that of increasing continuously. Adding nitrification inhibitors can improve relative $\mathrm{NO}_{3}-\mathrm{N}$ accumulation in surface soil $(0-40 \mathrm{~cm})$. The result suggests that nitrification inhibitors can reduce nitrate-nitrogen leaching downward, and improve surface soil nitrate-nitrogen accumulation.

\section{Acknowledgements}

This work was supported by National Key Technology Supported Program of China (Project 2011BAD32B03, 2008ZX07425-001), the China National Natural Science Foundation (Project 31040006).

\section{REFERENCES}

[1] O. Strebel, W. H. M. Dunynisveld and J. Bottcher, "Nitrate pollution of groundwater in western Europe,” Agriculture Ecosystem and Environment, Vol. 26, No. 3-4, 1989, pp. 189-214. 


\section{doi:10.1016/0167-8809(89)90013-3}

[2] J. F. Power and J. S. Schepers, "Nitrate Contamination of Groundwater in North America," Agriculture Ecosystem and Environment, Vol. 26, No. 3-4, 1989, pp. 165-187. doi:10.1016/0167-8809(89)90012-1

[3] J. L. Costa, H. Massone, D. Marrtinez, E. E. Soero, C. M. Vidal and F. Bedmar, "Nitrate Contamination of a Rural Aquifer and Accumulation in the Unsaturated Zone," Agricultural Water Management, Vol. 57, No. 1, 2002, pp. 33-47. doi:10.1016/S0378-3774(02)00036-7

[4] K. Chaney, "Effect of Nitrogen Fertilizer Rate on Soil Nitrate Content after Harvesting Winter Wheat," The Journal of Agricultural Science, Vol. 114, No. 2, 1990, pp. 171-176. doi:10.1017/S0021859600072166

[5] W. T. Cai, F. Chen, H. L. Zhang, J. Lei and X. Y. Wen, "Effects of Different Nitrogen Fertilization Levels on Yield of Cucumber, the Soil Nitrate-N Accumulation and the Soil Solution Nitrate-N Concentrations," Acta Agriculturae Boreali-Sinica, Vol. 24, No. 3, 2009, pp. 189193.

[6] E. E. Alberts and R. A. Spomer, "Dissolved Nitrogen in Runoff from Watersheds in Conservation and Conventional Tillage,” Journal Soil Water Consery, Vol. 40, No. 1, 1985, pp. 153-167.

[7] Z. P. Yang, M. C. Chen, Q. Zhang and J. J. Zhang, “Effects of Different Fertilizer Measurement on Nutrient Utilization in Cucumber and Nitrate Leaching Loss from Soil in Greenhouse," Journal of Soil and Water Conservation, Vol. 21, No. 2, 2007, pp. 57-60.

[8] H. B. Liu, Z. H. Li, Y. G. Zhang, W. L. Zhang and B. Lin, "Nitrate Contamination of Groundwater and Its Affecting Factors in Rural Areas of Beijing Plain," Accta PeDologica Sinica, Vol. 43, No. 3, 2006, pp. 405-413.

[9] S. D. Bao, "Soil and Agricultural Chemistry Analysis," China Agriculture Press, Beijing, 2000, pp. 263-270.

[10] S. P. Chen, X. Z. Wang, X. Z. Qian and J. Li, "Comparation and Relative Analyses on the Digesting Time and Results of Catalyst Mixtures of Plant Total Nitrogen in Kjeldahl Mothed,” Acta Agriculturae Boreali-Sinica, Vol. 21, 2006, pp. 19-22.

[11] X. M. Yuan, Y. A. Tong, X. Y. Yang, X. L. Li and F. S.
Zhang, "Effect of Phosphate Application on Soil Nitrate Nitrogen Accumulation," Plant Nutrition and Fertilizer Scieence, Vol. 6, No. 4, 2000, pp. 397-403.

[12] C. Y. Tian, Z. A. Lin, Y. B. Zuo, W. Y. Sun, S. G. Che, M. F. Cheng and B. Q. Zhao, "Review on Several Concepts on Fertilizer Nitrogen Recovery Rate and Its Calculation," Chinese Journal of Soil science, Vol. 42, No. 6, 2011, pp. 1531-1536.

[13] X. J. Zhang, G. F. Zhao, W. P. Zhu, X. Q. Chen, L. M. Wang, L. S. Wu and C. X. Hu, "Nitrogen Leaching from Vegetable Soil and Control Measures: A Review," Ecology and Environment, Vol. 13, No. 1, 2004, pp. 105-108.

[14] Y. Wei, L. P. Sun, S. Z. Wang, Y. Q. Wang, Z. X. Zhang, Q. Y. Chen, H. Z. Ren and L. H. Gao, "Effects of Different Irrigation Methods on Water Distribution and Nitrate Nitrogen Transport of Cucumber in Greenhouse," Transactions of the CSAE, Vol. 26, No. 8, 2010, pp. 67-72.

[15] P. Q. Guo, X. H. Li, K. A. Wang and N. Yang, "Effects of Different Levels N Application on the Nitrate Accumulation in Cucumber and Soil in Solar Greenhouse," Acta Agriculturae Boreali-Sinica, Vol. 24, No. 1, 2009, pp. 185-188.

[16] X. T. Ju and F. S. Zhang, "Nitrogen Accumulation and Its Implication to Environment in North China," Ecology and Environment, Vol. 12, No. 1, 2003, pp. 24-28.

[17] J. Yin, L. J. Fei and Y. F. Zhu, "Effect of Irrigation Quota on Soil Nitrate Nitrogen Concentration under Surge Irrigation,” Transactions of the CSAE, Vol. 25, No. 5, 2009, pp. 30-34.

[18] H. B. Liu, Z. H. Li, W. L. Zhang and B. Lin, "Study on N Use Efficiency of Chinese Cabbage and Nitrate Leaching under Open Field Cultivation,” Plant Nutrition and Fertilizer Science, Vol. 10, No. 3, 2004, pp. 286-291.

[19] L.Wang, F. M. Zhang and X. J. Wei, "Effects of Different Nitrogen Fertilization Levels on Quality and Yield of Cucumber Cultivated in Solar Greenhouse," Transactions of the CSAE, Vol. 23, No. 12, 2007, pp. 225-229.

[20] Z. L. Zhu, "Loss of Fertilizer N from Plants-soil System and the Strategies and Techniques for Its Reduction,” Siol and Environment Sciences, Vol. 9, No. 1, 2000, pp. 1-6. 